\title{
The Management of Retained Rectal Foreign Body
}

\author{
Ju Hun Kim, Eunhae Um, Sung Min Jung, Yong Chan Shin, Sung-Won Jung, Jae Il Kim, Tae Gil Heo, \\ Myung Soo Lee, Heungman Jun, Pyong Wha Choi \\ Department of Surgery, Ilsan Paik Hospital, Inje University College of Medicine, Goyang, Korea
}

Purpose: Because insertion of a foreign body (FB) into the anus is considered a taboo practice, patients with a retained rectal FB may hesitate to obtain medical care, and attending surgeons may lack experience with removing these FBs. We performed this study to evaluate the clinical characteristics of Korean patients with a retained rectal FB and propose management guideline for such cases based on our experience.

Methods: We retrospectively investigated 14 patients between January 2006 and December 2018. We assessed demographic features, mechanism of FB insertion, clinical course between diagnosis and management, and outcomes.

Results: All patients were male (mean age, 43 years) and presented with low abdominal pain $(n=2)$, anal bleeding $(n=2)$, or concern about a retained rectal FB without symptoms $(n=10)$. FB insertion was most commonly associated with sexual gratification or anal eroticism $(n=11,78.6 \%)$. All patients underwent general anesthesia for anal sphincter relaxation with the exception of 2 who underwent FB removal in the emergency department. FBs were retrieved transanally using a clamp $(\mathrm{n}=2)$, myoma screw $(\mathrm{n}=1)$, clamp application following abdominal wall compression $(\mathrm{n}=2)$, or laparotomy followed by rectosigmoid colon milking $(n=2)$. Colotomy and primary repair were performed in four patients, and Hartmann operation was performed in one patient with fecal peritonitis. No morbidity or mortality was reported. All patients refused postextraction anorectal functional and anatomical evaluation and psychological counseling.

Conclusion: Retained rectal FB is rare; however, colorectal surgeons should be aware of the various methods that can be used for FB retrieval and the therapeutic algorithm applicable in such cases.

\section{Keywords: Foreign body; Rectum; Management}

\section{INTRODUCTION}

A retained rectal foreign body $(\mathrm{FB})$ is one of the most unusual clinical presentations in the emergency department. In most cases, the FB (commonly, phallic substitutes) are purposely inserted for self-gratification associated with anal eroticism. Regardless of purpose, FB insertion into the anus is considered taboo; therefore, most patients are reluctant to seek medical attention and attempt self-retrieval via digital or instrumental manipula-

Received: Aug 29, 2019 - Revised: Sep 30, 2019 - Accepted: Oct 3, 2019 Correspondence to: Pyong Wha Choi, M.D., Ph.D.

Department of Surgery, Ilsan Paik Hospital, Inje University College of

Medicine, 170 Juhwa-ro, Ilsanseo-gu, Goyang 10380, Korea

Tel: +82-31-910-7622, Fax: +82-31-910-7319

E-mail: eacechoi@hanmail.net

ORCID: https://orcid.org/0000-0001-5777-8436

(C) 2020 The Korean Society of Coloproctology

This is an open-access article distributed under the terms of the Creative Commons Attribution NonCommercial License (https://creativecommons.org/licenses/by-nc/4.0) which permits unrestricted non-

commercial use, distribution, and reproduction in any medium, provided the original work is properly cited. tion, resulting in delayed presentation [1,2]. Moreover, history collection may not provide accurate information because patients may be too embarrassed to honestly disclose details regarding a self-inserted rectal FB. Despite the reluctance of patients with a retained rectal FB to seek medical attention, timely and accurate diagnosis is important, and physicians should refer the patient to a colorectal specialist.

Retained rectal FB is readily diagnosed via digital rectal examination or imaging studies, such as plain radiography and/or computed tomography $(\mathrm{CT})$. However, management of retained rectal FBs requires an individualized approach based on size, shape, nature, and location of the impacted FB and the degree of FB-induced rectal injury (which can range from mucosal injury to colorectal perforation) $[3,4]$. Therapeutic algorithms addressing this issue have been reported in the literature [5-7]. Most reports describe patients from Western countries, although there are 2 case reports from Asian countries [8,9].

We performed the present study to assess the clinical characteristics of Korean patients with a retained rectal FB and propose 
guidelines for management of such patients.

\section{METHODS}

We retrospectively investigated 14 patients diagnosed with retained rectal FB between January 2006 and December 2018, excluding cases secondary to oral ingestion of a FB. The following data were obtained from medical chart review: patient demographics; clinical presentation; cause of FB insertion; time interval between FB insertion and emergency department visit; nature, size, and location of the FB; grade of rectal injury; radiological findings; FB-induced complications; methods used for FB removal including operative details; and length of hospitalization. Initial evaluation after rectal FB insertion included history collection, physical examination, and laboratory investigations. During history collection, if the patient did not acknowledge anal eroticism but provided an unrealistic reason for anal insertion of the $\mathrm{FB}$, the case was categorized as FB insertion secondary to anal eroticism. Retained rectal FB was diagnosed based on clinical evidence obtained via history, physical examination, and radiological findings (plain radiography or CT). FB size was defined in terms of its largest diameter. Based on location, FBs were classified as low- or high-lying objects depending on whether they were palpable on digital rectal examination. The grade of rectal injury was assessed based on the Rectal Organ Injury Scale (ROIS) of the American Association for the Surgery of Trauma (AAST) as follows: grade I, contusion or hematoma without devascularization and/or partial-thickness laceration; grade II, laceration involving $<50 \%$ of the rectal wall circumference; grade III, laceration involving $>50 \%$ of the rectal wall circumference; grade IV, fullthickness laceration with extension into the perineum; grade $\mathrm{V}$, devascularized segment [10]. This study was approved by the Institutional Review Board of Ilsan Paik Hospital (No. 2019-04-012002 ) and was exempted from the requirement for informed consent.

\section{RESULTS}

\section{Patient demographics}

The mean age of the 14 patients was 43 years (range, 19 to 57

Table 1. Clinical features of patients with retained rectal foreign body (FB)

\begin{tabular}{|c|c|c|c|c|c|c|c|c|c|}
\hline No. & Year & $\begin{array}{l}\text { Age } \\
\text { (yr) }\end{array}$ & Presentation cause & $\begin{array}{l}\text { Reason provided } \\
\text { for insertion }\end{array}$ & $\begin{array}{l}\text { Colorectal } \\
\text { location }\end{array}$ & Inserted FB & $\begin{array}{l}\text { Retrieval } \\
\text { location }\end{array}$ & Extraction modality & $\begin{array}{l}\text { Hospital } \\
\text { stay (day) }\end{array}$ \\
\hline 1 & 2006 & 49 & $\begin{array}{l}\text { Concern about retained } \\
\text { rectal FB }\end{array}$ & Relief of constipation & Low & Drinking glass & $\mathrm{OR}$ & Colotomy and primary repair & 9 \\
\hline 2 & 2006 & 48 & Abdominal pain & Anal eroticism & Low & Cosmetic container & $\mathrm{OR}$ & $\begin{array}{l}\text { Transanal extraction after } \\
\text { laparotomy and milking }\end{array}$ & 7 \\
\hline 3 & 2007 & 49 & $\begin{array}{l}\text { Concern about retained } \\
\text { rectal FB }\end{array}$ & Anal eroticism & Low & Drinking glass & $\mathrm{OR}$ & Colotomy and primary repair & 8 \\
\hline 4 & 2008 & 29 & $\begin{array}{l}\text { Concern about retained } \\
\text { rectal FB }\end{array}$ & Anal eroticism & Low & Coffee can & $\mathrm{OR}$ & $\begin{array}{l}\text { Transanal extraction with } \\
\text { Kelly clamp }\end{array}$ & 9 \\
\hline 5 & 2009 & 44 & $\begin{array}{l}\text { Concern about retained } \\
\text { rectal FB }\end{array}$ & Anal eroticism & Low & Cosmetic lid & ER & Transanal manual extraction & 0 \\
\hline 6 & 2011 & 19 & $\begin{array}{l}\text { Concern about retained } \\
\text { rectal FB }\end{array}$ & Anal eroticism & Low & Perfume bottle & ER & Transanal manual extraction & 0 \\
\hline 7 & 2013 & 47 & $\begin{array}{l}\text { Concern about retained } \\
\text { rectal FB }\end{array}$ & Relief of hemorrhoid & High & Electric toothbrush & $\mathrm{OR}$ & $\begin{array}{l}\text { Transanal extraction with } \\
\text { Kelly clamp }\end{array}$ & 3 \\
\hline 8 & 2014 & 51 & $\begin{array}{l}\text { Concern about retained } \\
\text { rectal FB }\end{array}$ & Anal eroticism & Low & Radish & $\mathrm{OR}$ & $\begin{array}{l}\text { Transanal extraction with } \\
\text { myoma screw }\end{array}$ & 3 \\
\hline 9 & 2014 & 55 & Anal bleeding & Anal eroticism & High & Sexual device & $\mathrm{OR}$ & Colotomy and primary repair & 6 \\
\hline 10 & 2015 & 57 & $\begin{array}{l}\text { Concern about retained } \\
\text { rectal FB }\end{array}$ & Anal eroticism & Low & Cosmetic container & $\mathrm{OR}$ & Colotomy and primary repair & 9 \\
\hline 11 & 2015 & 42 & $\begin{array}{l}\text { Concern about retained } \\
\text { rectal FB }\end{array}$ & Anal eroticism & Low & Cosmetic container & $\mathrm{OR}$ & $\begin{array}{l}\text { Transanal extraction after } \\
\text { abdominal compression }\end{array}$ & 3 \\
\hline 12 & 2016 & 44 & Abdominal pain & Idiopathic & High & Twig & $\mathrm{OR}$ & Hartmann operation & 11 \\
\hline 13 & 2018 & 22 & Anal bleeding & Anal eroticism & Low & Sexual device & $\mathrm{OR}$ & $\begin{array}{l}\text { Transanal extraction after } \\
\text { abdominal compression }\end{array}$ & 2 \\
\hline 14 & 2018 & 42 & $\begin{array}{l}\text { Concern about retained } \\
\text { rectal FB }\end{array}$ & Anal eroticism & High & Sexual device & $\mathrm{OR}$ & $\begin{array}{l}\text { Transanal extraction after } \\
\text { laparotomy and milking }\end{array}$ & 4 \\
\hline
\end{tabular}

$\mathrm{OR}$, operating room; ER, emergency room. 
Volume 36, Number 5, 2020

years), and all patients were men. Most patients (11 of 14, 78.6\%) denied a history of underlying disease. Hypertension and chronic alcoholism were observed in 1 patient (7.1\%) each, and 1 patient presented with mental retardation and a history of Behcet disease. No patient reported a history of homosexuality or bisexuality. Clinical patient features are summarized in Table 1.

\section{Clinical presentation and diagnosis of a retained rectal FB}

Low abdominal pain and anal bleeding were the presenting complaints in 2 patients (14.3\%) each. Ten patients (71.4\%) were asymptomatic but presented with concerns regarding a retained rectal FB. Reasons provided for anal FB insertion included soothing hemorrhoids, relieving constipation (1 patient each, 7.1\%), and sexual gratification or anal eroticism (11 patients, $78.6 \%$ ). The cause of FB insertion in the patient with mental retardation was categorized as idiopathic because communication with the patient and accurate history collection were not possible. Among patients in whom FB insertion was associated with sexual gratification or anal eroticism, only 1 (7.1\%) admitted to this history and divulged that the present episode was the fourth instance of anal FB insertion. Ten patients (71.4\%) were reluctant to reveal details regarding FB insertion, and 3 of these 10 patients admitted to anal eroticism when the retained rectal FB was identified on plain radiography. However, the remaining 7 patients denied anal eroticism, and FB insertion was attributed to several seemingly implausible mechanisms including accidentally sitting on the object, anal massage, curiosity, and pranks during showering in 4 (28.4\%), 1 (7.1\%), 1 (7.1\%), and 1 patient (7.1\%), respectively.

All except the patient with mental retardation attempted self-retrieval of the rectal FB before visiting the emergency department. The mean interval between FB insertion and presentation was 10 hours (range, 1 to 48 hours). On digital rectal examination, the retained rectal $\mathrm{FB}$ could be palpated in 10 patients $(71.4 \%)$ at distances of 4 to $8 \mathrm{~cm}$ from the anal verge. The retained FB was pal-
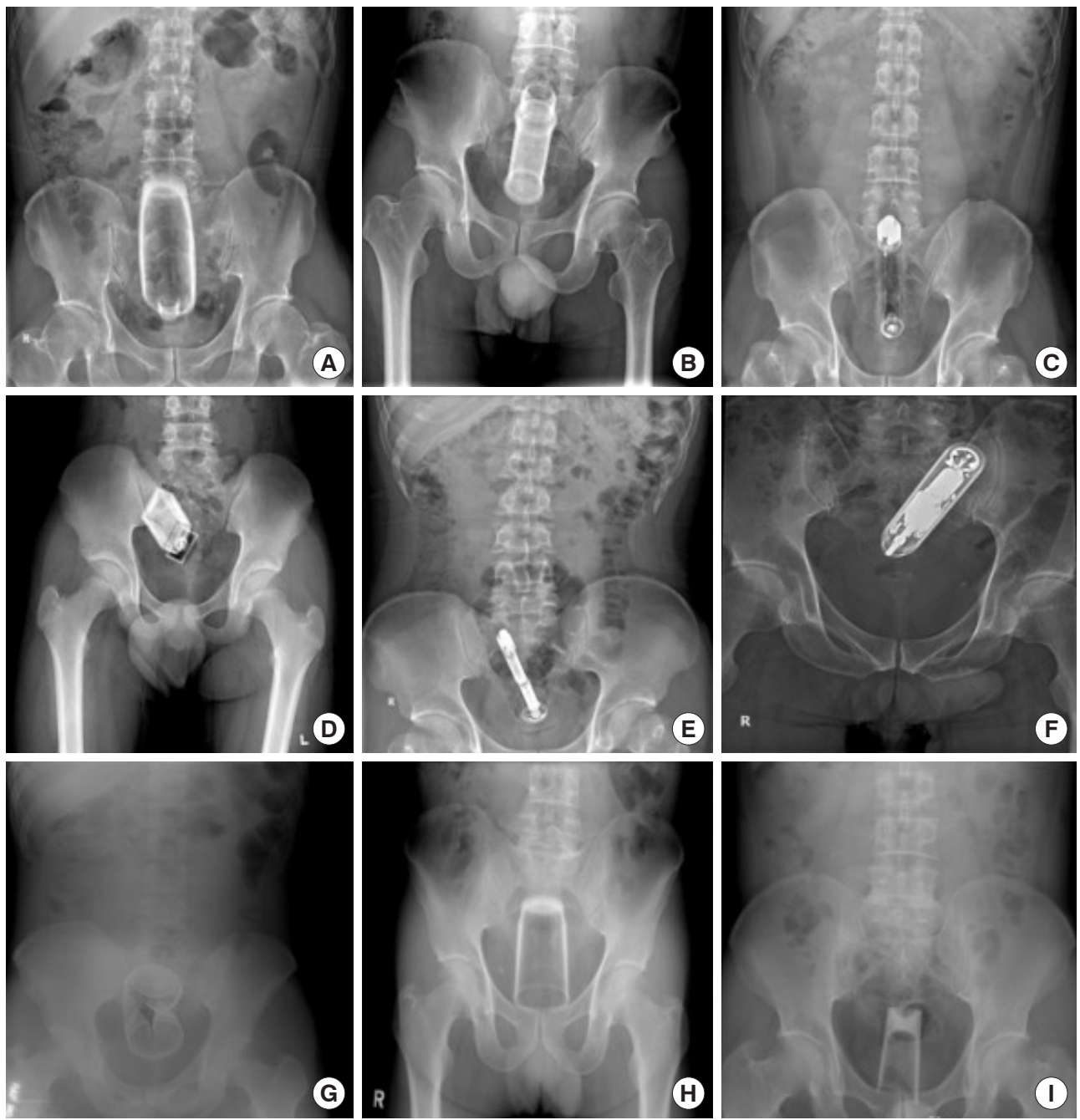

Fig. 1. Plain abdominal radiographs showing radiopaque retained rectal foreign bodies of various size and shape. 

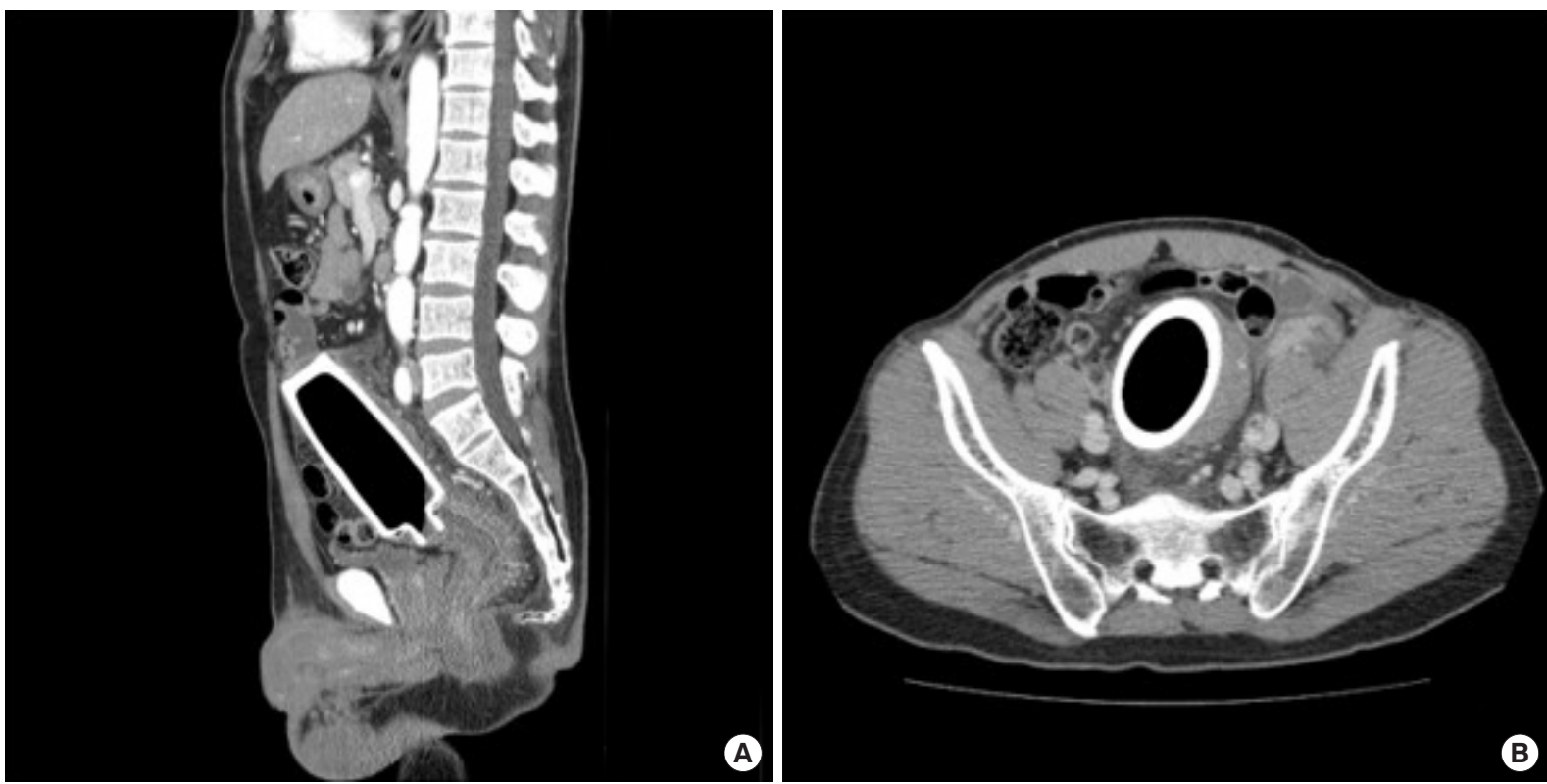

Fig. 2. Abdominopelvic computed tomography scans showing a retained rectal foreign body (plastic cosmetic container) with edema and thickening of the rectal wall: (A) sagittal and (B) axial views.

pated on abdominal examination in four patients (28.4\%). Only the patient with mental retardation developed signs of peritoneal irritation. Plain radiography was performed in all patients, and radiopaque FBs of various sizes and shapes were identified in 10 patients (71.4\%) (Fig. 1). Retained rectal FBs ranged from 5 to 40 $\mathrm{cm}$ in size, with a mean (standard deviation, SD) size of $13.5 \mathrm{~cm}$ $( \pm 9.1 \mathrm{~cm})$. CT was performed in 8 patients $(57.1 \%), 6$ of whom had a radiopaque $\mathrm{FB}$, while the other 2 patients had a radiolucent FB. In addition to the impacted rectal FB, we observed active bleeding and hematoma at the rectosigmoid junction in 2 patients (14.2\%) and pneumoperitoneum with panperitonitis in 1 patient (7.1\%). No complications were observed in the other 5 patients (35.5\%) (Fig. 2). Based on the AAST classification, 3 patients (21.4\%) had grade II rectal injury, while the other 11 had grade I rectal injury.

\section{Management of retained rectal FBs and outcomes}

All patients were referred to a colorectal surgeon immediately after diagnosis. FB extraction without anesthesia was attempted at the emergency room in 3 patients (21.4\%). The FB was successfully retrieved manually in 2 patients, while such retrieval failed in 1 patient. Sigmoidoscopic extraction was attempted in 1 patient; however, the FB could not be retrieved with grasping forceps. Therefore, 12 patients $(85.7 \%)$ were transferred to the operating room. Transanal extraction using a Kelly clamp was attempted under spinal anesthesia in 1 patient; however, failure to retrieve the FB necessitated induction of general anesthesia. Thus, general anesthesia was used in all patients transferred to the operating room. Among these patients, transanal retrieval of the FB was performed in 7 (58.3\%). Transanal extraction using only a Kelly clamp was successful in two patients; however, a myoma screw was required for $\mathrm{FB}$ retrieval in one patient with a retained radish (Fig. 3A). Transanal extraction using a Kelly clamp after lower abdominal compression and transanal extraction after laparotomy and milking of the rectosigmoid colon were performed in 2 patients (16.7\%) each. Transabdominal retrieval of the FB was performed in 5 patients (41.7\%). Colotomy and primary repair were performed in 4 patients (33.3\%), 2 of whom harbored an impacted drinking glass (Fig. 3B). In the patient with mental retardation, the FB was a twig measuring $40 \mathrm{~cm}$ in length that had penetrated the sigmoid colon with regional fecal contamination. Thus, Hartmann operation was performed, and colostomy takedown was performed 4 months postoperatively. Operative time ranged from 10 to 120 minutes, with a mean (SD) of 67 minutes ( \pm 35.6 minutes). Rectal FBs in the 14 patients in this study were categorized as follows: object of sexual gratification (3 patients), cosmetic container (3 patients), cosmetic container covered with a condom (1 patient), drinking glass (2 patients), cosmetic lid (1 patient), coffee can (1 patient), electric toothbrush (1 patient), radish covered with a plastic bag (1 patient), and a twig (1 patient) (Fig. 4). No postoperative morbidity or mortality was observed. Overall mean length of hospitalization, excluding the two patients who underwent FB removal at the emergency department, was 6.2 days (range, 2 to 11 days), and a liquid diet was initiated 2.5 days (mean) postoperatively (range, 1 to 5 days). Postextraction sigmoidoscopy was performed in only 1 patient during hospitalization, and 2 patients (16.7\%) were referred to a psychologist, although both refused psychological consultation. The overall 

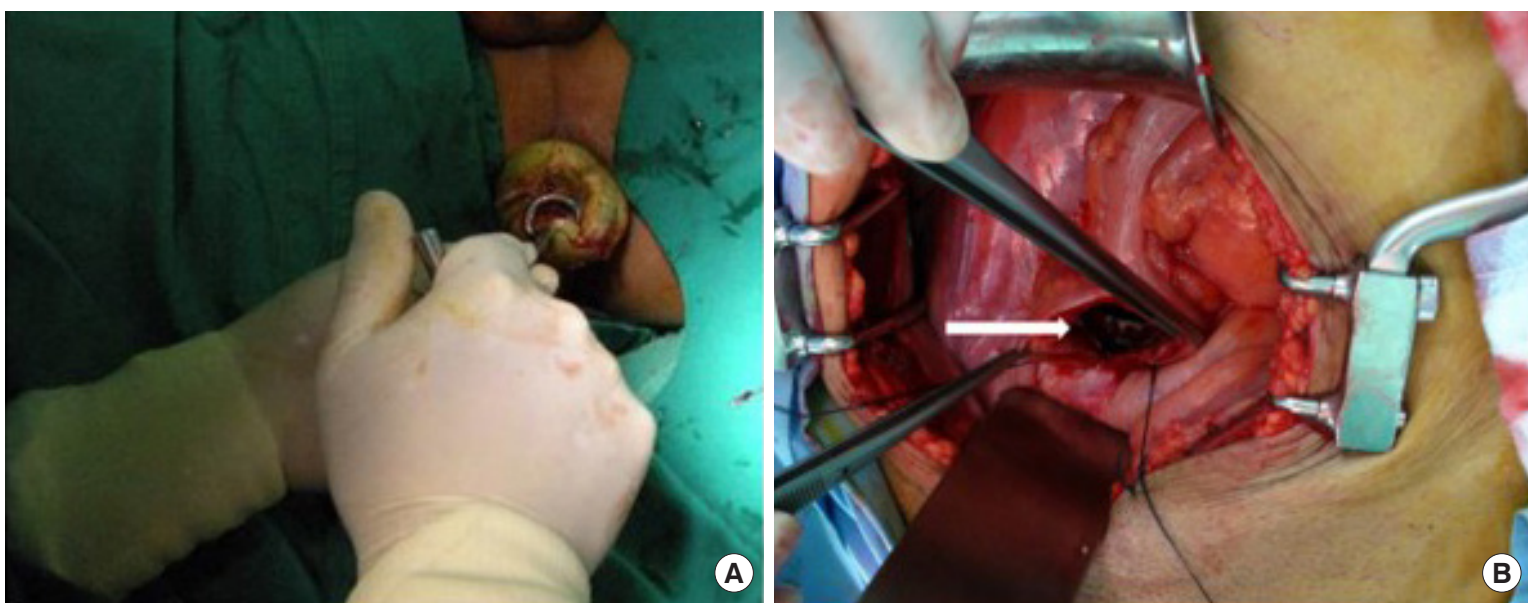

Fig. 3. Intraoperative images showing retrieval of a rectal foreign body. (A) A myoma screw was used for transanal retrieval of the rectal foreign body (radish). (B) A drinking glass (arrow) was extracted after colotomy at the rectosigmoid junction.
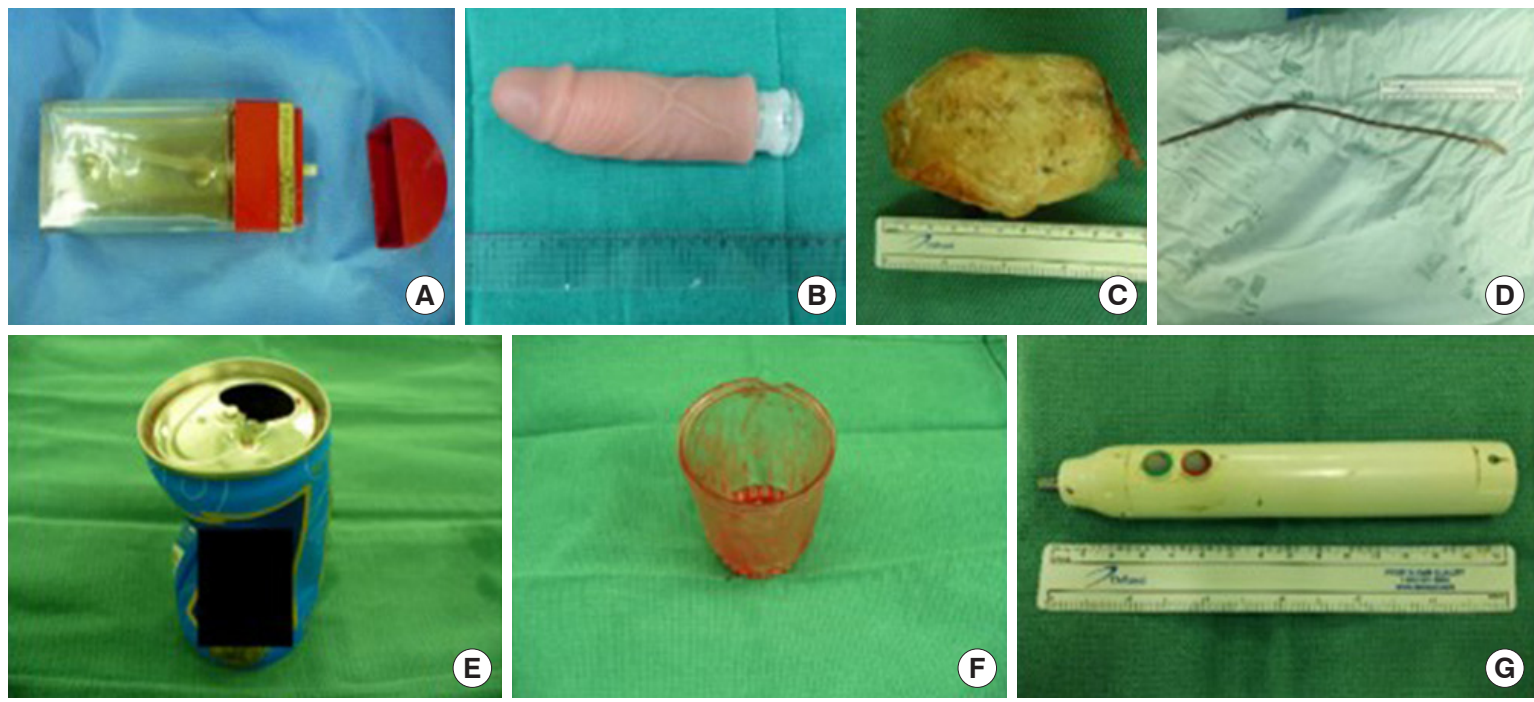

Fig. 4. Images showing a variety of extracted rectal foreign bodies. (A) A perfume bottle, (B) a phallic substitute for sexual gratification, (C) a radish covered with a plastic bag, (D) a twig, (E) a coffee can, (F) a drinking glass, and (G) an electric toothbrush.

mean follow-up was 2.6 weeks (range, 0 to 24 weeks), and 3 patients (21.4\%) were lost to follow-up. During follow-up, no patient underwent postextraction anorectal functional and anatomical evaluation with manometry and transanal ultrasonography or psychological consultation.

\section{DISCUSSION}

Management guidelines for retained rectal foreign bodies are not well established, and most of the existing therapeutic algorithms are from Western countries. Because cases from Asia are particularly rare, we performed this study to establish management guideline for Koreans with a retained rectal FB; this is the first study to report management guidelines for patients with retained rectal FB in Korea.

Although a retained rectal FB is one of the most uncommon clinical presentations in emergency departments, it can no longer be considered a rare entity due to the increasing number of studies being reported in Western countries. However, the incidence of this condition in Asian countries remains unclear [11]. Cultural differences and attitudes toward patients with retained rectal $\mathrm{FB}$ may affect the incidence of presentation with a retained rectal $\mathrm{FB}$ in clinical practice; the true incidence in Asians may be higher than previously reported because of the diversity of sexual preferences in Asian societies. Even though retained rectal FB is rare, and the number of the patients observed over a period of 13 years 
in a single Korean institute was only 14, clinicians at emergency departments, particularly colorectal surgeons, should ensure accurate history collection and imaging studies for prompt diagnosis and optimal therapeutic intervention in patients with retained rectal FB.

Reasons for anal FB insertion vary widely and include relief from hemorrhoids or constipation, concealment of drugs, secondary gains in patients with psychiatric disorders, assault, and sexual gratification or anal eroticism. Autoeroticism for sexual gratification appears to be the most common reason for FB insertion, and most patients are sexually active males between 20 and 40 years of age, as observed in the present study [1-6]. Careful history collection is important for accurate diagnosis in the emergency department. However, anal FB insertion for sexual gratification is considered taboo; because of the embarrassment associated with this practice, most patients do not provide an accurate history. Therefore, such cases are diagnostic challenges. Patients may fabricate a history and attribute the retained rectal FB to false causes. Previous studies have reported that only $10 \%$ to $30 \%$ of patients provide an accurate history because of embarrassment [1, $2,5,11]$. Our findings concur with those of previous studies; only 1 patient was forthcoming about the reason for FB insertion, and most patients denied a history of sexual practices that could have contributed to rectal FB insertion. Therefore, in patients with a high index of clinical suspicion for retained rectal FB associated with anal eroticism or sexual gratification, physicians should be mindful of patient confidentiality. A nonjudgmental attitude and respect for the patient's privacy are imperative to establish and maintain rapport with such a patient. Gaining patient trust is essential to obtain sensitive but valuable information pertaining to retained rectal FB to enable prompt diagnosis and management.

Patients with retained rectal FB usually present with anal or pelvic pain, anal bleeding, constipation, and acute abdomen in cases with infection or perforation $[1-3,11]$. The incidence rate of perforation is approximately $10 \%[5,12]$. Most patients attempt selfretrieval of FBs, which leads to delayed presentation and can cause perforation due to pressure necrosis or penetrating injury of the rectosigmoid colon. The perforation rate observed in the present study was similar to the rates observed in previous studies, and most patients were asymptomatic, presenting only with concerns associated with a retained rectal FB.

Accurate history collection provides important diagnostic clues in patients with retained rectal FB, and detailed physical examination including digital rectal examination and imaging is necessary for diagnostic confirmation even in the absence of an accurate history $[3,4,6]$. Abdominal examination can detect perforationinduced peritonitis, and occasionally, a large high-lying FB may be palpated, as was observed in this case series. In patients with a high-lying FB, plain radiography is useful, particularly in those with an uncertain history. Plain radiography enables visualization of most rectal FBs to determine size, shape, and location $[2,6,13]$. However, radiolucent FBs such as fish bones, plastic objects, and vegetables may not be readily visualized $[2,13]$. Even though the indications for CT are not conclusively established in such cases, patients with complications such as perforation or high-lying rectal FB that cannot be confirmed by plain radiography require CT. In addition to radiographic examination, sigmoidoscopy is useful to confirm rectal FB $[3,4]$. However, endoscopic evaluation may be of limited diagnostic utility in patients with complications, and this modality may be more useful as a therapeutic intervention. In the present study, CT was performed in eight patients. Excluding patients with radiolucent $\mathrm{FB}$ or peritonitis, the indications for CT were not documented in detail. Nonvisualization of an FB on plain radiography does not exclude its presence. Thus, CT is indicated in rare instances for diagnosis; however, routine CT may not be justified in patients with retained rectal FB.

Management of retained rectal FB should be individualized depending on size, shape, nature, location, and interval between insertion and diagnosis of the FB and complications. Hemodynamically unstable patients or those with signs of peritonitis, indicating perforation, should be transferred to the operating room for laparotomy. In hemodynamically stable patients without evidence of peritonitis, extraction methods should be determined based on the attributes of the FB. Transanal or transabdominal approaches are most commonly used for FB retrieval. Transanal extraction is the most common approach used in patients with rectal $\mathrm{FB}$, and $60 \%$ to $70 \%$ of FBs can be successfully removed transanally [14]. If the rectal FB can be palpated by digital examination, it may be possible to remove it manually transanally or with instruments such as a Kelly clamp, Kocher clamp, and ring forceps. However, despite palpation of a rectal FB on digital rectal examination, FB retrieval may be challenging depending on size, shape, and contour of the FB. Therefore, various extraction devices and methods have been reported, including an obstetric vacuum device, a Foley catheter, Sengstaken-Blakemore probes, and electromagnets to extract metallic FBs [12, 15-18]. Regardless of the technique used, adequate relaxation of the anal sphincter prior to removal is important for successful FB retrieval. Small low-lying FBs may be removed manually without anesthesia; however, spinal or general anesthesia is necessary in most cases. Anesthesia reduces anal sphincter spasm and facilitates the use of an anal retractor for enhanced visualization and exposure of the field, thereby improving the $\mathrm{FB}$ retrieval rate $[2,4,18,19]$. Moreover, downward compression of the lower abdomen to milk the FB for transanal extraction is easier in anesthetized patients. Excluding 2 patients who underwent FB removal at the emergency department, all patients underwent general anesthesia in the operating room. Kelly clamp was used to grasp the FB in all except the patient in whom a myoma screw was used because the FB was a radish that could not be grasped easily using the Kelly clamp. Thus, from our experience, colorectal surgeons should be familiar with a variety of extraction methods and be willing to improvise for transanal retrieval of rectal FBs.

Sigmoidoscopic retrieval using polypectomy snare or biopsy 
forceps may be useful for retrieval of small FBs that are more proximally located in the rectum or in the distal sigmoid colon. This procedure obviates the need for anesthesia to relax the anal sphincter and facilitates visualization of the rectal mucosa and the FB $[2,11]$. However, large FBs or those without an adequate grasping edge are not easily retrievable using only sigmoidoscopy. Thus, a novel transanal approach using a single-incision laparoscopic instrument, namely a SILS port, has been reported. Although this approach requires induction of general anesthesia, it enables easier retrieval of FBs than with sigmoidoscopy and can be used in obscure cases that do not meet the indications for sigmoidoscopy or surgery [9].

Surgical extraction through laparotomy is indicated in patients with peritonitis; however, this approach is usually considered the last resort after failure of transanal retrieval, primarily because of the morbidity associated with laparotomy $[2,11,13]$. Therefore, minimally invasive approaches, such as laparoscopic pushing and milking the FB distally followed by transanal extraction, have been reported [20,21]. Although these techniques may be attempted prior to laparotomy, they require laparoscopic expertise and can only be used in patients with smooth FB due to risk of perforation [2].

In the present study, we could not determine the risk factors for laparotomy due to the small sample size; however, FBs retained over $>2$ days, those that are $>10 \mathrm{~cm}$ in size or sharp objects, and those that have migrated into the sigmoid colon are considered predictors of surgical intervention [3]. In the case of fragile FBs such as drinking glasses (with the opening directed proximally), negative pressure within the glass may produce a consequent suction effect, drawing the mucosa into the opening. In such cases, Foley catheters have been used to overcome the suction effect [22]. However, this technique may not be feasible when the opening of the glass is directed distally, as was observed in 2 patients in our series. Furthermore, mucosal edema around the opening may impede transanal retrieval of the FB. Therefore, we consider a glass FB to be a potential indication for laparotomy because manipulation during transanal extraction can cause breakage of the glass in the rectum, precipitating further injury and/or serious complications [8].

For transanal removal of FBs that are not sharp and/or fragile in patients without complications, milking the FB distally into the rectum can be attempted during laparotomy, before proceeding with colotomy $[2,13]$. If this method fails or if the FB is sharp and/or fragile, colotomy is necessary for FB removal. Primary repair without a diversion stoma can be performed in most such cases. However, in patients with complications such as perforation with fecal peritonitis or necrosis, Hartmann's operation or resection and primary anastomosis with or without stoma should be

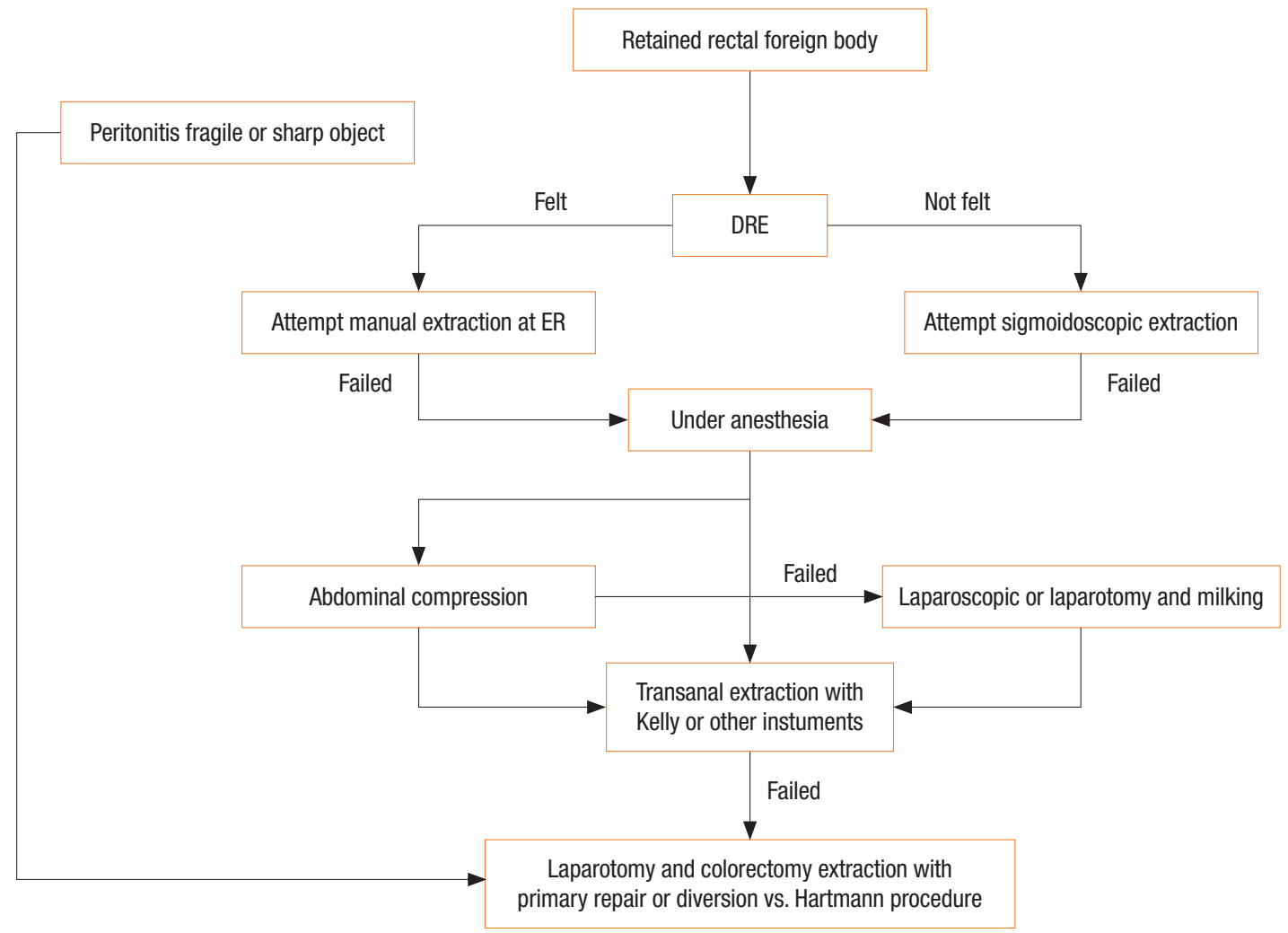

Fig. 5. Management algorithm for retained rectal foreign bodies. DRE, digital rectal examination; ER, emergency room. 
performed depending on patient hemodynamic stability, degree of contamination, and grade of rectal injury $[23,24]$. Even though AAST-ROIS is usually applied in cases of blunt and penetrating trauma, it may be used in patients with retained rectal FB. Notably, most injuries secondary to retained rectal FBs are categorized as grade I or II, as observed in this case series [2].

Several therapeutic algorithms for retained rectal FBs have been published [1, 3, 5-7]. Although their fundamental principles are similar, these algorithms are rather complex for real-world clinical application. Based on our experience, we developed a simplified personalized therapeutic algorithm for patients with retained rectal FB (Fig. 5).

Sigmoidoscopy is usually recommended following rectal FB removal to evaluate the anorectal mucosa and the extent of injury. Although a few authors have advocated sigmoidoscopy as a mandatory procedure, it may not be obligatory because it may predispose to complications, and close clinical observation is adequate for postextraction care $[3,7,11,18]$. In our study, postextraction sigmoidoscopy was performed in only one patient because most refused further evaluation. Although evaluation of the anorectal mucosa and determination of the extent of injury are essential, information obtained from postextraction sigmoidoscopy does not usually affect postextraction management, and close clinical observation is adequate in most cases. Therefore, in our opinion, this procedure is not mandatory after FB removal.

In addition to being a surgical and medical issue, insertion of FB into the anus may indicate psychological disturbances, necessitating systematic postextraction management. Therefore, psychological consultation is important prior to discharge to treat psychological trauma, avoid recurrence, and manage underlying psychiatric disorders, if any. However, most patients refuse psychological counseling, as was observed in the present study $[2,11$, 13]. Given this clinical scenario, the attending colorectal surgeon should make efforts to help patients overcome their reluctance to undergo counseling and provide support without inflicting emotional trauma.

In the present study, all patients refused postextraction evaluation for anorectal anatomy and function in addition to refusing psychological consultation. Usually, most patients with retained rectal FBs show acceptable outcomes if they receive timely and optimal management $[2,3,5]$. In our case series, none of the patients complained of postextraction anal incontinence during the short follow-up period. However, postextraction complications such as sphincter injury, fistula formation, and stenosis cannot be excluded. Anal incontinence secondary to sphincter injury is a significant issue. Thus, evaluation for anal sphincter anatomy and function is necessary after FB extraction.

This study investigated the clinical characteristics of patients with retained rectal FB and aimed to establish management guidelines in such patients. One limitation of this study is that clinical patterns and optimal management guidelines could not be conclusively established in Koreans with retained rectal FB be- cause of the limited number of patients included in this study. Other limitations include the short follow-up period, lack of postextraction anorectal functional and anatomical evaluation, and patient refusal to undergo psychological consultation. Given that the incidence rate of retained rectal FB in Koreans appears to be lower than that in Westerners, large-scale multicenter studies are warranted to determine the characteristics of retained rectal FB in Koreans and to establish optimal therapeutic guidelines.

In conclusion, although retained rectal FB is an unusual presentation, colorectal surgeons should be familiar with the various extraction methods. Moreover, it is important to establish rapport with the patient through a proactive and nonjudgmental approach to encourage postextraction anorectal evaluation and psychological consultation to minimize postextraction sequelae and psychological trauma.

\section{CONFLICT OF INTEREST}

No potential conflict of interest relevant to this article was reported.

\section{REFERENCES}

1. Clarke DL, Buccimazza I, Anderson FA, Thomson SR. Colorectal foreign bodies. Colorectal Dis 2005;7:98-103.

2. Goldberg JE, Steele SR. Rectal foreign bodies. Surg Clin North Am 2010;90:173-84.

3. Lake JP, Essani R, Petrone P, Kaiser AM, Asensio J, Beart RW Jr. Management of retained colorectal foreign bodies: predictors of operative intervention. Dis Colon Rectum 2004;47:1694-8.

4. Kasotakis G, Roediger L, Mittal S. Rectal foreign bodies: a case report and review of the literature. Int J Surg Case Rep 2012;3:111-5.

5. Cawich SO, Thomas DA, Mohammed F, Bobb NJ, Williams D, Naraynsingh V. A management algorithm for retained rectal foreign bodies. Am J Mens Health 2017;11:684-92.

6. Kurer MA, Davey C, Khan S, Chintapatla S. Colorectal foreign bodies: a systematic review. Colorectal Dis 2010;12:851-61.

7. Smith MT, Wong RK. Foreign bodies. Gastrointest Endosc Clin N Am 2007;17:361-82.

8. Choi PW, Lee JM, Heo TG, Park JH, Lee MS, Kim CN, et al. Rectal foreign body (glass cup) extracted by laparotomy. J Korean Surg Soc 2008;74:448-51.

9. Han HJ, Joung SY, Park SH, Min BW, Um JW. Transanal rectal foreign body removal using a SILS port. Surg Laparosc Endosc Percutan Tech 2012;22:e157-8.

10. Moore EE, Cogbill TH, Malangoni MA, Jurkovich GJ, Champion HR, Gennarelli TA, et al. Organ injury scaling, II: pancreas, duodenum, small bowel, colon, and rectum. J Trauma 1990;30:1427-9.

11. Huang WC, Jiang JK, Wang HS, Yang SH, Chen WS, Lin TC, et al. Retained rectal foreign bodies. J Chin Med Assoc 2003;66:607-12.

12. Coskun A, Erkan N, Yakan S, Ylldirim M, Cengiz F. Management of rectal foreign bodies. World J Emerg Surg 2013;8:11. 
13. Ayantunde AA. Approach to the diagnosis and management of retained rectal foreign bodies: clinical update. Tech Coloproctol 2013;17:13-20.

14. Cologne KG, Ault GT. Rectal foreign bodies: what is the current standard? Clin Colon Rectal Surg 2012;25:214-8.

15. Feigelson S, Maun D, Silverberg D, Menes T. Removal of a large spherical foreign object from the rectum using an obstetric vacuum device: a case report. Am Surg 2007;73:304-6.

16. Hellinger MD. Anal trauma and foreign bodies. Surg Clin North Am 2002;82:1253-60.

17. Johnson SO, Hartranft TH. Nonsurgical removal of a rectal foreign body using a vacuum extractor: report of a case. Dis Colon Rectum 1996;39:935-7.

18. Rodriguez-Hermosa JI, Codina-Cazador A, Ruiz B, Sirvent JM, Roig J, Farres R. Management of foreign bodies in the rectum. Colorectal Dis 2007;9:543-8.

19. Cirocco WC. Anesthesia facilitates the extraction of rectal foreign bodies. Gastrointest Endosc 2000;52:452-3.
20. Berghoff KR, Franklin ME Jr. Laparoscopic-assisted rectal foreign body removal: report of a case. Dis Colon Rectum 2005;48:19757.

21. Rispoli G, Esposito C, Monachese TD, Armellino M. Removal of a foreign body from the distal colon using a combined laparoscopic and endoanal approach: report of a case. Dis Colon Rectum 2000;43:1632-4.

22. Ahmed A, Cummings SA. Novel endoscopic approach for removal of a rectal foreign body. Gastrointest Endosc 1999;50:8724.

23. Demetriades D, Murray JA, Chan L, Ordonez C, Bowley D, Nagy $\mathrm{KK}$, et al. Penetrating colon injuries requiring resection: diversion or primary anastomosis? An AAST prospective multicenter study. J Trauma 2001;50:765-75.

24. Herr MW, Gagliano RA. Historical perspective and current management of colonic and intraperitoneal rectal trauma. Curr Surg 2005;62:187-92. 